\begin{tabular}{|c|c|c|}
\hline 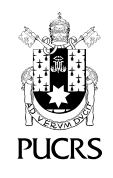 & $\begin{array}{l}\text { ESCOLA DE } \\
\text { HUMANIDADES }\end{array}$ & $\begin{array}{l}\text { Revista Digital do Programa de Pós-Graduação em Letras da PUCRS } \\
\text { Letrônica, Porto Alegre, v. 13, n. 3, p. 1-6, jul.-set. } 2020 \\
\text { e-ISSN: } 1984-4301\end{array}$ \\
\hline http://dx & $\mathrm{rg} / 10.15448 / 1984-4301.2020 .3 .37535$ & \\
\hline
\end{tabular}

\title{
O Momento Literário, de João do Rio, e o espírito das polêmicas
}

\author{
João do Rio's O Momento Literário and the polemical spirit
}

\section{Silvia Maria Azevedo ${ }^{1}$ orcid.org/0000-0001-7679-1919 silrey@uol.com.br}

Recebido em: 1 abr. 2020. Aprovado em: 8 abr. 2020. Publicado em: 30 out. 2020.
Resumo: Traço estruturante do pensamento do final do século XIX e início do século XX, a polêmica, quer como gênero literário, quer como meio de propagação de ideias, quer ainda como modo de autoafirmação, foi uma prática constante entre a intelectualidade brasileira. No inquérito de João do Rio, O momento literário (1909), vários foram os escritores que se manifestaram acerca das polêmicas que, travadas na impressa, configuravam-se como estratégia de legitimação e ingresso no campo literário. O objetivo do artigo é recuperar o depoimento dos entrevistados no sentido de identificar a polêmica como expressão constitutiva da república das letras no Brasil, assim também a trajetória de polemistas de alguns letrados que responderam ao inquérito de João do Rio.

Palavras-chave: Polêmicas. Inquéritos. João do Rio.

Abstract: Structural feature of the thought of the end of the 19th century and beginning of the 2oth century, the polemic, both as a literary genre, as a means of propagating ideas, and as a way of self-affirmation, was a constant practice among Brazilian intellectuals. In João do Rio's survey, O Momento Literário (1909), there were several writers who spoke about the controversies that, fought in the press, were configured as a strategy of legitimation and entry into the literary field. The objective of the article is to recover the interviewees' testimony in order to identify the controversy as a constitutive expression of the republic of letters in Brazil, as well as the trajectory of polemicists of some scholars who responded to João do Rio's inquiry.

Keywords: Controversial. Surveys. João do Rio.

\section{Introdução}

De regresso de uma de suas numerosas viagens, Medeiros e Albuquerque, sempre muito bem informado sobre as novidades literárias na Europa, teria sugerido a João do Rio fazer uma série de reportagens com escritores da literatura brasileira, a exemplo do que então se fazia na França e na Itália. (MAGALHÃES JÚNIOR, 1978, p. 48) Entusiasmado, o cronista carioca lançou-se à tarefa, passando a publicar na Gazeta de Notícias (RJ), entre março e maio de 1905, entrevistas com autores brasileiros, reunidas em livro, que saiu pela Garnier, em 1909, com o título de O momento literário.

Àépoca, João do Rio tinha 23 anos e apenas uma obra publicada, As religiões do Rio (Garnier, 1904), mas vinha colaborando na imprensa desde 1899, em A Cidade do Rio, dirigido por José do Patrocínio, onde permaneceu até 1900. Desde então, o cronista carioca envolveu-se em inúmeras disputas com seus pares jornalistas, de tal forma que se pode dizer que o próprio organizador do inquérito representa o espirito de polêmica a contaminar O momento literário.

Apesar das críticas favoráveis à obra, não faltou quem acusasse 
João do Rio de ser um plagiador de Jules Huret, que em 1891 realizou para o L'Écho de Paris entrevistas com sessenta e quatro importantes escritores acerca da situação do Naturalismo na França, publicadas, no mesmo ano, em Enquête sur l'évolution littéraire. A crítica, no entanto, não se sustentava, pois que o inquérito de João do Rio, denominado "reportagem experimental", nova modalidade de crítica literária, de caráter informativo e menos reflexivo, propunha questões mais amplas, leituras de formação, o momento atual da literatura brasileira, literaturas regionais, relação entre literatura e imprensa.

Dividido em quatro partes - "Antes", Entrevistas (36), "Os que não responderam" e "Depois" - O momento literário se abre em tom de conversa, na reprodução do diálogo entre o narrador-entrevistador e um interlocutor não identificado, possivelmente Medeiros e Albuquerque, a quem o livro é dedicado, e se estende pelas entrevistas, muitas delas permeadas pela descontração e oralidade. Há que se acrescentar que o inquérito de João do Rio, como ele mesmo vai dizer em "Antes", vinha ao encontro da curiosidade do público sobre a vida dos escritores (dada à exposição na imprensa) e menos em relação às suas obras. Algumas entrevistas foram realizadas pessoalmente, outras, por carta (para os escritores que não estavam no Rio ou fizeram essa opção), metodologia diferente daquela empregada na organização das histórias literárias mais convencionais, aspecto a partir do qual pode ser lido o inquérito de João do Rio. Detalhes sobre o cenário de realização das conversas com os entrevistados (lugar, relacionamento entre os escritores), convivem com alta dose de inventividade, a promover o diálogo entre a objetividade e fidelidade da entrevista e o imaginativo da criação literária.

Quanto ao contexto de realização de $O$ momento literário, trata-se de um tempo de crise de escolas literárias e valores culturais, a repercutir na literatura brasileira do final do século XIX e início do XX, quando passam a coexistir diversas orientações estilísticas distintas (Realismo, Naturalismo, Parnasianismo, Simbolismo, romance social, poesia de ação), responsável pelo clima de tensão que impregna as respostas de alguns dos entrevistados.
Essa atmosfera de "tudo que é sólido desmancha no ar" encontra-se representada no título do livro de João do Rio - "momento literário" - a apontar para o caráter instantâneo da obra - "curiosidade de verão", nas palavras de João do Rio - algo passageiro, fugaz, a contrastar com a proposta de uma cartografia da história literária e cultural brasileira, ainda que essa tradição possa estar aberta a revisões e deslocamentos de autores e obras literárias, nessa outra possivel interpretação do inquérito de 1909.

Se a crítica, de maneira geral, foi favorável ao livro de João do Rio, o mesmo não aconteceu entre os entrevistados, pois que alguns se mostraram reticentes quanto ao inquérito, como foi o caso de João Ribeiro, que, de início, ficou bastante "pé atrás", quando abordado pelo entrevistador:

A primeira vez que falei a João Ribeiro da possibilidade de um inquérito a respeito do momento literário, foi à porta do Garnier, às 3 da tarde, hora em que aparecem os literatos e os diplomatas para a conversação de praxe.

João Ribeiro estava num dos seus dias de irritação.

Arriscaria dizer que me recebeu com três pedras na mão, se não tivesse a certeza de que era muito maior o número delas (RIO, 2019, p. 54).

O clima de prevenção contra as entrevistas talvez decorresse, de um lado, do temor dos entrevistados à exposição pública de suas opiniões, muito embora essa fosse a condição de muitos deles como jornalistas, de outro lado, pelo teor das perguntas formuladas que foram as seguintes:

- Para sua formação literária quais os autores que mais contribuiram?

Das suas obras qual a que prefere?

- Especificando mais ainda: quais, dentre os seus trabalhos, as cenas ou capitulos, quais os contos, quais as poesias que prefere?

- Lembrando separadamente a prosa e a poesia contemporâneas, parece-lhe que o momento atual, no Brasil, atravessamos um periodo estacionário, há novas escolas (romance social, poesia de ação, etc.), ou há a luta entre antigos e modernos? Neste último caso, quais são elas? Quais os escritores contemporâneos que as representam? Qual a que julga destinada a predominar? - O desenvolvimento dos centros literários dos Estados tenderá a criar literaturas à parte?

- O jornalismo, especialmente no Brasil, foi um fator bom ou mau para a arte literária? (RIO, 2019, p. 43-44, grifo do autor). 
A primeira pergunta - autores e obras que contribuiram para a formação dos entrevistados - . caía-se no lugar comum de apresentar o escritor como leitor, permitia também compor um quadro de referências históricas, literárias e culturais que marcaram o Brasil na segunda metade do século XIX. Olavo Bilac (1865-1918), por exemplo, lia diariamente dois escritores, Renan e Cervantes, o primeiro, historiador e filósofo que exerceu grande influência sobre boa parte da intelectualidade brasileira daquele periodo; o segundo, um clássico de todos os tempos. João Ribeiro, por sua vez, iniciou sua formação com os livros da biblioteca do avô, em especial a coleção de O Panorama (1837-1844) e do Almanaque de Lembranças Luso-Brasileiras (1851-1932), aquele, o primeiro grande periódico português de divulgação cultural, dirigido por Alexandre Herculano (1810-1877), este, publicação de caráter enciclopédico, fundada por Alexandre Magno de Castilho (1803-1860).

A segunda pergunta, as preferências do autor em relação à própria obra, focalizava o escritor como leitor e crítico dos seus trabalhos. As respostas recebidas foram variadas, e por vezes divertidas, como a de Nestor Vitor que disse ter predileção pela obra que ainda não escreveu, enquanto Sílvio Romero, que nunca primou pela modéstia, como ele mesmo assumiu, declarou ter preferência por todos os seus trabalhos.

A questão acerca do estado atual da poesia e da prosa no Brasil teria sido motivada em função da convivência das várias tendências estéticas, mencionadas acima, muito delas conflitantes. Para alguns entrevistados, o momento literário era marcado, não pela decadência das letras brasileiras, mas tratava-se de uma época de transição, caso de Raimundo Correia, opinião contra a qual se opõe Elísio de Carvalho, para quem o período estacionário pelo qual passavam as letras nacionais tinha como causa principal a turbulência dos primeiros anos da República.

A pergunta sobre a formação dos centros literários nos Estados, e se essas ações poderiam criar literaturas à parte, possivelmente foi motivada pela fundação de agremiações e os movimentos culturais em várias capitais e cidades brasileiras no contexto da proclamação da República. Quase todos os escritores interrogados negaram a possibilidade de separação da literatura nacional em segmentos regionais, com argumentos muitas vezes semelhantes, que poderiam ser sintetizados na opinião de Clóvis Beviláqua, para quem a literatura brasileira era uma só. Garcia Redondo, por sua vez, achava que a influência de Portugal era ainda tão forte entre nós, que não tínhamos sequer uma literatura que pudesse ser chamada de brasileira. Apenas Coelho Neto responde afirmativamente à questão, invocando Euclides da Cunha como escritor que estabeleceu, em termos definitivos, a contraposição entre o sertanejo do Norte e o homem do Sul.

A última pergunta, a influência positiva ou negativa do jornalismo sobre a literatura, inscreve-se no contexto da modernização da imprensa, da profissionalização, visibilidade e consagração do escritor, assim como da massificação da produção veiculada em jornais e revistas, a apontar para o misto de empolgação e resistência com que era visto o trabalho na imprensa. Aqueles que deram respostas positivas quanto à influência do jornalismo sobre a arte literária invocaram aspectos, como pagamento, divulgação, experiência, caso de Curvelo de Mendonça, entre outros. As respostas negativas, que podem ser agrupadas em argumentos comuns, como mercantilismo, banalização e falta de tempo, têm como representantes Guimarães Passos e Luís Edmundo.

Mas são as respostas à terceira pergunta - o momento atual da poesia e da prosa no Brasil - as que tornam perceptivel a tensão em que convivem diversas orientações estilisticas distintas, representadas pelos entrevistados. O primeiro a apontar para esse clima de rivalidade é ainda João Ribeiro, ao declarar:

\footnotetext{
Não gosto, absolutamente não gosto dos nossos últimos poetas lem referência aos simbolistas]; falo dos últimos, recentíssimos. Basta dizer que não os leio e que ainda que o quisesse não os podia ler. E digo com a máxima sinceridade que, em abrindo uma folha, prefiro ler um anúncio de leilão a um soneto. É a nossa poesia de hoje uma coisa pior que péssima [...] (RIO, 2019, p. 58-59).
} 
Mais à frente, Ribeiro dá a entender que as polêmicas entre literatos configuram o ambiente de discordância entre as várias expressões estéticas no final do século XIX e início do século XX:

A verdade é que não sinto e não entendo, não alcanço o que querem os nossos poetas. Quer v. mais? Já transpus os limites da discrição, e numa sociedade primitiva e guerreira como esta, democrática pela força das coisas sem nenhuma educação liberal, e em que a regra é eliminar os discordantes, com o que disse já estou mal parado.

Peço, se se interessa pela minha paz de espirito, que acrescente ai numa entrelinha: há algumas exceções honrosas... (RIO, 2019, p. 59-60).

Em resposta à questão sobre a formação de literaturas à parte, Medeiros e Albuquerque é de opinião que entre nós não existiam escolas literárias, mas que

[...] infelizmente [...] existem grupos e a luta, a repulsa desses grupos, que ocultamente se guerreiam e, por vezes, de modo mesquinho, sob o disfarce do desintimidade. É doloroso, é lastimável, é uma porcaria em que só aproveitam os medíocres, os moedas-secas e os attachés de uns e de outros lados (RIO, 2019. p. 118, grifo do autor).

Luis Edmundo acha que as polêmicas literárias são coisa do passado, o clima intelectual no Brasil, na atualidade, é de "indiferença", embora sua resposta possa também dizer o contrário, na alusão mordaz à crítica praticada por Medeiros e Albuquerque:

O ardor das velhas pugnas literárias é coisa que já não existe entre nós. A não ser o sr. Medeiros e Albuquerque, que se diverte, às vezes, com a leviandade de certos escritores novos e que transforma as suas crônicas literárias em teatrinho Guignol, onde os desgraçados que lhe caem nas mãos dançam o velho desengonço do Pai João, nada mais de ouve ou se vê (RIO, 2019, p. 131-132).

Outro entrevistado, Nestor Vitor, é ele mesmo, tanto pelo temperamento quanto pelas polêmicas em que esteve envolvido, como a defesa do poeta Cruz e Sousa das críticas de Alberto de Oliveira, expressão do ambiente de disputa que caracteriza o campo literário, no Brasil da época. Quando da realização do inquérito, porém, de volta de Paris, Nestor Vitor está mudado:
Recebo-o na volta de sua longa viagem. Nestor Vitor está transformado. A violência, aquele ar de pedagogo zangado com que procurava convencer os discipulos, desapareceu. É um cidadão que passou por Paris, que viveu em Paris, que civilizou todas as arestas do temperamento na polidez de Paris.

Três anos antes faria reflexões a propósito do meu inquérito, reflexões onde haveria decerto alguns desaforos, alguns axiomas, algumas ironias e muito talento. No momento em que lhe pedia as suas ideias, entretanto, sorriu (RIO, 2019, p. 147).

Certos entrevistados são o protótipo do espírito da polêmica, como o padre Severiano de Resende, conhecido pelos "dotes violentos do seu estilo combativo e pletórico" (RIO, 2019, p. 171), a se manifestar logo no início da entrevista:

De S. Paulo mandaram-te muitas respostas? perguntou o padre. Não mandaram era natural. Era natural. Eu expatrio S. Paulo do Brasil. Houve um tempo que a Pauliceia era um viveiro de poetas e prosadores. Tempos idos! Hoje há na Academia uns bacharéis em germe muito bem vestidos e muito pedantes; e o escol literário vive em retiro. No entanto, em S. Paulo podia haver um grande movimento literário, havendo lá, como há, talentos raros. Não falo por exemplo de um Garcia Redondo, que é o arquétipo do imbecil relapso na sua mania de literatejar à outrance [...] (RIO, 2019, p. 172).

E mais à frente, ao fazer referência a Venceslau de Queirós (que não foi convidado a participar do inquérito) -, conhecido como o Baudelaire paulistano, pelo teor de seus versos simbolistas -, o padre Severiano não tem papas na língua:

\begin{abstract}
- Hás de me perguntar por que é que estou esquecendo o Venceslau de Queirós? Mas este, meu caro, é super abominável. Pretensioso e orgulhoso, este detestável escriba é capaz de matar a quem disser que os seus versos são maus. E não há quem os faça pior, fazendo-os em abundância, há mais de trinta anos... (RIO, 2019, p. 173).
\end{abstract}

Outro entrevistado, Félix Pacheco - embora aclamado como "chefe do simbolismo" (RIO, 2019, p. 196), não acredita que no Brasil haja escolas literárias, ou antes, a única escola que viceja entre nós "é a dos alhos e bugalhos" (RIO, 2019, p. 197), isto è, a Academia Brasileira de Letras:

Essa escola [...], sofre de um mal que não sei se existe em medicina, mas que é positivamente a tuberculose dos recém-nascidos. [...] Medeiros e Albuquerque, que é diretor da instrução, faria 
uma obra de caridade se olhasse um pouco para a pobrezita. Porque com o Zé Veríssimo, positivamente a coisa não vai lá das pernas! [...] O homem é dos tais que não enxergam uma polegada diante do nariz [...] (RIO, 2019, p. 197).

A Academia Brasileira de Letras é atacada igualmente por Frota Pessoa, vista como um espaço em que os imortais perpetuavam rixas eternas, como a travada entre Lúcio de Mendonça, terrivel polemista, e Garcia Redondo sobre a nacionalidade do poeta português Gonçalves Crespo. Para o autor de Crítica e polêmica (1902), a ABL não passava de "[...] uma sociedade funerária, com o exclusivo escopo de prantear os defuntos imortais e de receber novos imortais candidatos à vida eterna" (RIO, 2019, p. 219).

O clima de oposição entre os novos (muitos dos quais aspirantes à Academia, como foi o caso de João do Rio) e os antigos (os medalhões convertidos em imortais) é sintetizado por Fábio Luz, médico baiano e militante anarquista:

Atualmente o Brasil literário atravessa um periodo de estagnação e as lutas se travam entre os consagrados, que procuram amesquinhar e depreciar os trabalhos dos novos, no juto receio de que lhes venham fazer sombra, e os novos, que aspiram ser velhos, medalhões consagrados, demolindo reputações bem ou mal adquiridas (RIO, 2019, p. 231, grifo do autor).

A solução para o impasse, segundo Fábio Luz, estaria na senda da literatura de cunho social, que permitiria insuflar um sopro de vida à literatura esterilizante então praticada: "arte de filigrana bela para ver e inteiramente inútil; boa arrumação de palavras, paisagens sem figuras, figuras sem a iluminação do olhar" (RIO, 2019, p. 231).

O espírito das polêmicas invade ainda a penúltima parte de O momento literário - "Os que não responderam" - da qual constam Machado de Assis, Graça Aranha, Aluísio Azevedo, Artur Azevedo, Alberto de Oliveira, Gonzaga Duque, Emílio de Meneses e José Veríssimo. A inclusão dessa seção no livro, acompanhada das justificativas dos autores, expressava a preocupação de João do Rio em dar uma satisfação ao público leitor quanto à ausência de nomes notáveis da literatura brasileira no inquérito: "Há nomes que deviam aqui estar, mas que não estão porque a isso se opuseram uma sensibilidade grande, a vaidade doentia, a noção de responsabilidades graves e principalmente talvez a balbúrdia das ideias" (RIO, 2019, p. 325).

O tom mordaz, a ironia ferina do jornalista desqualificava, no entanto, as razões apresentadas por aqueles que não responderam à entrevista, somados ao fato de que a inclusão da penúltima seção no livro por si só apontava para o espírito de desforra de João do Rio em relação aos corifeus da literatura brasileira que rejeitaram colaborar na sua iniciativa.

Machado de Assis, esquivo e reticente, preocupado em não ferir suscetibilidades, postergou indefinidamente responder ao inquérito, que era a forma obliqua de recusá-lo. Como troco, João do Rio irá registrar episódio cômico da carreira de funcionário público de Machado, o dia em que por não ter podido atender ao pedido que alguém lhe fizera, acaba acompanhando-o numa xícara de café (ele que só tomava chá), o que lhe valeu tremenda dor de cabeça.

Quanto a Graça Aranha, João do Rio não é menos sarcástico, em razão de o autor de Canãa ter se recusado responder às perguntas, ancorado no princípio de que se deve escrever pouco, o que levou o cronista a evocar Plutarco, Luciano e Zola, que "[...] poriam as mãos na cabeça se o ouvissem; todos os trágicos abririam a boca de pasmo" (RIO, 2019, p. 326-327).

Aluísio Azevedo foi outro a quem João Rio não poupou de sua ironia ferina. Em carta enviada de Cardiff, o então cônsul do Brasil na Inglaterra invocava o tempo consumido em despachar montanhas de papeis como motivo pelo qual não respondia ao inquérito, a merecer comentário sarcástico do cronista: "O cônsul inibe o escritor de responder!" (RIO, 2019, p. 327).

Ao pouco apreço, para não dizer o descaso, com que a enquete foi recebida por Artur Azevedo e Gonzaga Duque, João do Rio respondeu na forma do registo lacônico, a revidar a afronta recebida: "Artur Azevedo não disse nada/Gonzaga Duque esqueceu" (RIO, 2019, p. 327).

O mesmo laconismo, revelador das cisões e disputas no campo literário, perpassa a informação de que Alberto de Oliveira e Emilio de Meneses "adiaram indefinidamente as respostas" (RIO, 2019, p. 327). 
José Verissimo mereceu comentário mais extenso, e por isso mais impiedoso e mordaz, em razão dos motivos por que o crítico não respondeu às perguntas formuladas por João do Rio: primeiramente porque não gostou do inquérito, depois porque via nesse tipo de investigação "um processo de fazer livros à custa dos outros." (RIO, 2019, p. 327). O cronista não deixou passar a ocasião para desferir suas setas venenosas contra José Veríssimo: "Tamanha amabilidade impediu-me de insistir, e obrigou-me a pedir a Deus que a produção da literatura nacional aumente. Só assim o sr. Veríssimo não insistirá na pesca da Amazônia para continuar a sua série de Escritos e escritores" (RIO, 2019, p. 327).

\section{Considerações finais}

Assim, para concluir, pode-se dizer que as respostas dos entrevistados, em especial sobre à 3. ${ }^{a}$ e $4 .^{\text {a }}$ questões propostas em O momento literário expressam, de maneira inquestionável, a rivalidade entre os grupos literários que integravam o cânone da época. Ao dar voz às celebridades que participaram do inquérito, o clima de oposição entre os escritores brasileiros é posto a nu, imagem que vinha desmistificar a representação olímpica dos mesmos junto ao leitor. Por trás da exposição pouco favorável às idealizações, está o entrevistador João do Rio, figura maquiavélica a propor questões que ele estava certo do seu potencial explosivo.

A preocupação em ser fiel às palavras dos entrevistados, como tantas vezes o cronista vai invocar no livro, não esconde a intenção de alguém que se delicia na exibição de um lado desconhecido da vida dos medalhões da literatura brasileira, movida por ódios, invejas e perseguições. Espírito iconoclasta, a inclusão dos "bastidores" de O momento literário, na forma da seção "Os que não responderam", escancara aquilo que os ausentes não disseram de maneira explícita, ou seja, não queriam ter os seus nomes associados ao de João do Rio, e muito menos prestigiar o trabalho do outro, como disse José Veríssimo com outras palavras.

Movido pela vontade férrea de, a qualquer preço, fazer parte do seleto grupo da república brasileira, João do Rio sabia que, para ter sucesso, deveria seguir à risca essa espécie de programa de extermínio do oponente, próprio do espírito das polêmicas, que Félix Pacheco deixou registrado em seu depoimento: "Quem deseja vencer, deverá começar demolindo, porque, no fim de contas, só essa figura iconoclasta pode ter a virtude de arrombar a porta e facilitar a entrada" (RIO, 2019, p. 198).

\section{Referências}

MAGALHÃES JÚNIOR, Raimundo. A vida vertiginosa de João do Rio. Rio de Janeiro: Civilização Brasileira, 1978.

RIO, João do. O momento literário. Organização, introdução e notas de Sílvia Maria Azevedo e Tania Regina de Luca. São Paulo: Rafael Copetti Editor, 2019.

\section{Sílvia Maria Azevedo}

Professora adjunta do Departamento de Literatura da Faculdade de Ciências e Letras da Universidade Estadual Paulista "Júlio de Mesquita Filho" (Unesp), em Assis, SP, Brasil. Lider do Grupo de Pesquisa do CNPq: Polêmicas Intelectuais na América Latina entre os séculos XIX e XX: retórica, cultura e história.

\section{Endereço para correspondência}

Silvia Maria Azevedo

Universidade Estadual Paulista "Júlio de Mesquita Filho"

Departamento de Literatura

Av. Dom Antônio, 2100

Parque Universitário

19806900

Assis, SP, Brasil 